\title{
A randomised trial of hip protector use by frail older women living in their own homes
}

\author{
I D Cameron, R G Cumming, S E Kurrle, S Quine, K Lockwood, G Salkeld, T Finnegan
}

Injury Prevention 2003;9:138-141

\begin{abstract}
Objectives: To investigate the efficacy and effectiveness of hip protectors in frail community living older women.

Design: Randomised controlled trial.

Setting: Aged care health services in New South Wales, Australia.

Patients: 600 women 74 years of age or more (mean age 83 years), who had two or more falls or one fall requiring hospital admission in the previous year, and who lived in their own homes.

Intervention: Use of hip protectors.

Main outcome measures: Adherence with use of hip protectors, falls, incidence of hip fracture, and adverse effects of use of hip protectors. Results: Adherence was approximately 53\% over the duration of the study and hip protectors were worn at the time of $51 \%$ of falls in the intervention group. The risk of hip fracture when falling while wearing hip protectors, compared with a fall with no hip protectors in place, was significantly reduced (relative risk (RR) 0.23 , 95\% confidence interval (Cl) 0.08 to 0.67 ). On an intention to treat analysis, 21 and 22 hip fractures occurred in the intervention and control groups respectively ladjusted RR 0.92, $95 \% \mathrm{Cl} 0.51$ to 1.68 ). Three users of hip protectors sustained a hip fracture while wearing properly applied protectors, while 16 hip protector users $(5 \%)$ developed minor local complications.

Conclusions: Hip protectors prevent hip fractures in community dwelling older women if worn at the time of a fall. The overall effectiveness of hip protectors was not established in this study, because of incomplete adherence with use of the protectors, and limited statistical power.
\end{abstract}

See end of article for authors' affiliations

Correspondence to: Associate Professor lan Cameron, Rehabilitation Studies Unit, University of Sydney, PO Box 6, Ryde NSW 1680, Australia ianc@mail.usyd.edu.au ip protectors have been shown to reduce the incidence of hip fracture in residents of nursing homes. ${ }^{1}$ While the relative risk reduction is approximately $50 \%$ in these studies, they have involved people at high risk of hip fracture and have used a cluster randomisation design that, with the analytic methods used, may result in an overestimate of the statistical significance of any treatment effect.

One reported study of hip protectors included some people living in their own homes with support services. However, this group was only approximately $30 \%$ of all study participants, and they were living in outpatient care units for supported living. ${ }^{2}$

The effectiveness of hip protectors among older people living in their own homes is likely to be dependent on a number of factors, with adherence (also called acceptance or compliance by some) likely to be the most crucial. ${ }^{34}$ In the community it will be the user herself who has the major influence on adherence, whereas in residential aged care facilities, or supported accommodation at home, the support of healthcare staff provides additional external encouragement and assistance to use the protectors.

As the majority of people who break their hip live in their own homes and are women, we have conducted a study to examine the effectiveness of hip protectors in this group. We hypothesised that use of external hip protectors, and encouragement from trained nurses to comply with their use, would reduce the incidence of hip fracture in frail older women.

\section{METHOD}

\section{Recruitment}

Enrollment started in May 1996 and continued until February 1999. Final follow up interviews were completed in February 2001. Inclusion criteria were: female gender; living in their own homes (rather than residential aged care facilities); in contact with aged care health services; age 74 years or older; two or more falls, or one fall requiring hospital treatment in the last year; at least one hip without prior surgery; ability to speak English; and, in the opinion of the nurse recruiting the participant, having sufficient cognitive function to give informed consent, likely to continue to live at home for three months, and to survive for at least one year. Ethical approval for the study was obtained from the relevant human research ethics committees.

\section{Study design and intervention}

Participants were randomly allocated to intervention (use of hip protectors and contact with the "adherence" nurse) and control groups, using stratification by the presence or absence of cognitive impairment (as judged by the nurse recruiting the participant) and whether recruited from home or hospital. Randomisation took place after collection of baseline data, using a numbered and sealed envelope containing allocation details. The randomisation sequence was computer generated independent of the study staff. Participants allocated to wear hip protectors were encouraged to wear them for two years (or until a hip fracture occurred). They were asked to wear the hip protectors at all times when out of bed during the day, and at night if needing to go to the toilet more than once. Two adherence nurses were employed to supply and fit the protectors and to encourage adherence with their use. Three visits by the nurses, followed by two telephone contacts, were made for routine contact with participants. If the participants were not adhering, additional telephone contacts or visits were arranged at the discretion of the adherence nurse. Approximately one third of participants required additional contact

Abbreviations: $\mathrm{Cl}$, confidence interval; $\mathrm{RR}$, relative risk 
Table 1 Baseline characteristics of study subjects according to group allocation; values are number $(\%)$ unless stated otherwise

\begin{tabular}{|c|c|c|}
\hline Characteristic & $\begin{array}{l}\text { Intervention group } \\
(n=302)\end{array}$ & $\begin{array}{l}\text { Control group } \\
(n=298)\end{array}$ \\
\hline Mean (SD) age (years) & $83.2(5.1)$ & $83.0(4.9)$ \\
\hline Mean (SD) weight $(\mathrm{kg})$ & $59.0(15.6)$ & $58.6(11.9)$ \\
\hline \multicolumn{3}{|l|}{ Fracture history } \\
\hline Hip fracture & $76(25)$ & $76(26)$ \\
\hline Other fracture & $174(58)$ & 176 (59) \\
\hline \multicolumn{3}{|l|}{ Falls in past year } \\
\hline 1 & $96(32)$ & $98(33)$ \\
\hline 2 & $84(28)$ & $106(36)$ \\
\hline$>2$ & $122(40)$ & $94(32)$ \\
\hline History of stroke & $44(15)$ & $54(18)$ \\
\hline History of Parkinson's disease & $15(5)$ & $9(3)$ \\
\hline Hormone replacement therapy use (ever) & $34(11)$ & $33(11)$ \\
\hline Psychotropic medication use (current) & $52(17)$ & 49 (16) \\
\hline Cigarette smoker (ever) & 118 (39) & $104(35)$ \\
\hline \multicolumn{3}{|l|}{ Activities of daily living score* } \\
\hline 100 & $195(64)$ & $173(58)$ \\
\hline 95 & $51(17)$ & 55 (19) \\
\hline 90 & $21(7)$ & 33 (11) \\
\hline$>90$ & $35(12)$ & $37(12)$ \\
\hline \multicolumn{3}{|l|}{ Mental state questionnaire (errors) $\dagger$} \\
\hline 0 & $148(49)$ & $136(46)$ \\
\hline 1 & $47(16)$ & $74(25)$ \\
\hline 2 & 54 (18) & 51 (17) \\
\hline$>2$ & 53 (17) & 37 (12) \\
\hline \multicolumn{3}{|l|}{ Self rated health } \\
\hline Excellent & $18(6)$ & $23(8)$ \\
\hline Very good & $76(25)$ & $67(23)$ \\
\hline Good & $113(38)$ & $114(39)$ \\
\hline Fair & $72(24)$ & $69(23)$ \\
\hline Poor & $21(7)$ & $21(7)$ \\
\hline \multicolumn{3}{|l|}{ Health related quality of lifef } \\
\hline Mean (SD) PCS score & $38.3(11.2)$ & $36.8(11.5)$ \\
\hline Mean (SD) MCS score & $51.3(9.3)$ & $51.6(9.1)$ \\
\hline Carer involved§ & $226(75)$ & $214(72)$ \\
\hline \multicolumn{3}{|l|}{ Location when recruited } \\
\hline Hospital & 51 (17) & $48(16)$ \\
\hline Community & $251(83)$ & $250(84)$ \\
\hline \multicolumn{3}{|c|}{$\begin{array}{l}\text { *Barthel index score. } \\
\text { TThe mental status score is the numbers of errors on the Short Portable Mental Status Questionnaire. } \\
\text { ¥As measured by the Medical Outcomes Study Short Form } 12 \text { health status measure. }{ }^{10} \\
\text { §Carer involved means that the participant had a family member, friend, or carer who was in regular } \\
\text { (weekly or greater) contact with the participant. } \\
\text { MCS, Mental Composite Score; PCS, Physical Composite Score. }\end{array}$} \\
\hline
\end{tabular}

because of limited adherence. If a participant moved to a residential aged care facility adherence with use of the hip protectors was encouraged with education provided to the staff of the facility. If there was still non-use of the protectors after three visits by the nurses, no further efforts were made to try to convince participants to wear the protectors. Participants in the hip protector group were initially provided with four pairs of hip protectors (semirigid shields sewn into modified underwear), and replacement protectors were provided to many fully adherent participants during the study. Additional details of the study method have been published elsewhere. ${ }^{6}$

\section{Outcome measures}

The major outcomes assessed were adherence with use of hip protectors, falls, incidence of hip fractures and other injuries, and adverse events. Adherence was measured as the amount of time that hip protectors were worn during the day. The assessment of falls was based on self report at four monthly telephone interviews. The ascertainment of hip fractures and other injuries was based initially on self report with follow up of radiography reports and hospital records as a secondary check.

The nature of the intervention (wearing hip protectors or not) meant that participants and the research and adherence nurses were not blinded. However, the radiologists who diag- nosed hip fractures were unaware of participation in the study and thus were blinded.

\section{Statistical analyses}

We anticipated that hip protectors would result in a 50\% reduction in hip fracture incidence ${ }^{7}$ and planned to follow up participants for two years. The sample size required with a 5\% annual hip fracture incidence in the control group (power $80 \%$, alpha $5 \%$ ) is about 500 per group, assuming that $10 \%$ of participants died during follow up. Recruitment ceased with a sample size of 600 participants due to lack of further funding.

The primary analysis assessed the difference in hip fracture incidence between the hip protector and control groups on an intention-to-treat basis using survival analysis based on Cox proportional hazards models. The relative risk of a hip fracture in a fall while wearing hip protectors compared with the risk in a fall when not wearing protectors was calculated using a Generalised Estimating Equations approach based on a negative binomial distribution. Analyses were performed using the SAS/STAT and STATA statistical packages.

\section{RESULTS}

\section{Participants}

A total of 600 frail older women were randomised. Figure 1 provides details of participant flow in this study. At entry to 


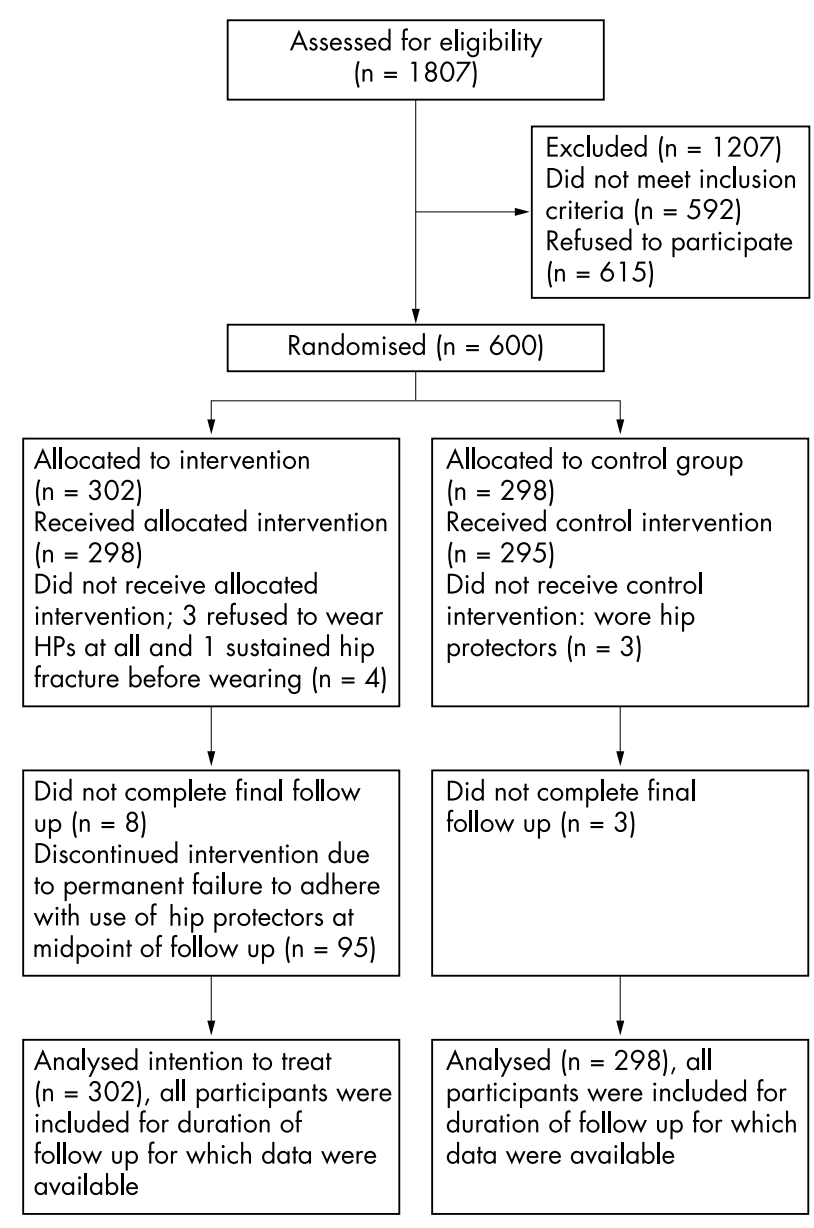

Figure 1 Participant flow: community hip protector study.

the study there were no important differences between intervention and control groups (table 1). In summary, participants were elderly (mean age 83 years) and had significant disability. Twenty five percent had a history of hip fracture, 35\% had more than two falls in the last year, and 30\% rated their health as fair or poor.

During the study, $13 \%$ of subjects died (33 in the intervention group and 46 in the control group, $\mathrm{p}=0.10$ ).

\section{Adherence with use of the hip protectors}

Adherence with hip protector use was recorded at approximately one month, three months, one year, 18 months, and 24 months after entry to the study (see table 2). The percentage adherence shown is the amount of time that the hip protectors were being worn during the day in the interval preceding the adherence contact. Adherence was satisfactory for approxi-
Table 3 Fractures during follow up according to group allocation

\begin{tabular}{lll}
\hline Fracture site & $\begin{array}{l}\text { Intervention } \\
\text { group }\end{array}$ & $\begin{array}{l}\text { Control } \\
\text { group }\end{array}$ \\
\hline Lower limb & 21 & 22 \\
Hip & 8 & 6 \\
Pelvis* & 3 & 6 \\
$\quad$ Other & & \\
Upper limb & 12 & 6 \\
$\quad$ Wrist* \\
Humerus/shoulder & 5 & 5 \\
Other & 3 & 4 \\
\hline
\end{tabular}

*One participant in the intervention group had two pelvic fractures, one participant in the intervention group had two wrist fractures.

mately one year with $57 \%$ of participants reporting that they were wearing the protectors for at least half of every day. However, at the follow up assessments at 18 and 24 months, this had fallen to $50 \%$ and $42 \%$ of surviving participants.

Mean (SD) longitudinal adherence was 53\% (39\%) and median longitudinal adherence was $54 \%{ }^{11}$ In $51 \%$ of falls occurring in participants in the intervention group, hip protectors were in place at the time of the fall.

\section{Falls}

There were no significant differences in the total number of falls, multiple falls, or falls causing injury requiring hospital care between the two groups. There were 1437 falls during follow up with 798 in the intervention group (a mean of 2.70 falls per person) and 639 in the control group (a mean of 2.20 in the control group), a relative risk of falls of 1.23 (95\% confidence interval (CI) 0.89 to 1.57 ). There was no difference between groups in the percentage of people who had two or more falls during follow up: $46 \%$ in the hip protector group and $44 \%$ in the control group (relative risk (RR) $1.03,95 \%$ CI 0.86 to 1.24$)$.

\section{Hip fractures and fall injuries}

The relative risk of hip fracture in a fall while wearing a hip protector compared with a fall while not wearing was calculated as 0.23 (95\% CI 0.08 to 0.67 ). Using an intention to treat analysis, there was no significant difference in the incidence of hip fractures in the intervention and control groups. Twenty one hip fractures occurred in the intervention group while twenty two occurred in the control group; (RR $0.92 ; 95 \%$ CI 0.51 to 1.68$)$. The relative risk adjusted for mental status score and falls history (because of some baseline imbalance in these factors) was 0.93 (95\% CI 0.51 to 1.69 ).

There were 31 peripheral, non-hip fractures in 25 people in the intervention group; and 27 peripheral non-hip fractures in 25 people in the control group (table 3 ).

Table 2 Adherence with use of hip protectors; values are number (\%)

\begin{tabular}{|c|c|c|c|c|c|}
\hline \multirow[b]{2}{*}{ Adherence } & \multicolumn{5}{|c|}{ Adherence visit (median days from study entry until visit) } \\
\hline & $1(25)(n=297)$ & $2(99)(n=280)$ & $3(351)(n=263)$ & $4(542)(n=249)$ & $5(733)(n=242)$ \\
\hline $0 \%$ & 55 (19) & $63(23)$ & $95(36)$ & $106(43)$ & $130(54)$ \\
\hline $1 \%-49 \%$ & $11(4)$ & $25(9)$ & 18 (7) & $18(7)$ & $10(4)$ \\
\hline $50 \%$ & $23(8)$ & $28(10)$ & $23(9)$ & $25(10)$ & $13(6)$ \\
\hline $51 \%-75 \%$ & $13(4)$ & $10(4)$ & $7(3)$ & $5(2)$ & $6(2)$ \\
\hline $76 \%-99 \%$ & $15(5)$ & $13(4)$ & $3(1)$ & 0 & $2(1)$ \\
\hline $100 \%$ & $180(60)$ & $141(50)$ & $117(44)$ & $95(38)$ & 81 (33) \\
\hline Missing data & 0 & 1 & 5 & 7 & 8 \\
\hline Deaths & 4 & 12 & 20 & 28 & $32 *$ \\
\hline Hip fracture & 1 & 9 & 14 & 18 & $20^{*}$ \\
\hline
\end{tabular}




\section{Adverse events}

Three hip fractures occurred while participants were wearing hip protectors. In two the hip protectors appear to have been ineffective in a fall backwards, and the third involved a motor vehicle accident and was not typical of falls causing hip fracture. There were no other significant adverse effects reported. Minor skin irritation or infection, that was judged by the research nurses as being caused by the hip protectors, occurred in 16 hip protector users $(5 \%)$. There were no reports of decubitus ulceration as a result of use of the protectors. Five falls that occurred while wearing hip protectors were reported as causing significant bruising to the upper thigh.

\section{DISCUSSION}

This randomised trial shows that use of hip protectors by people in the community prevents hip fractures if the protectors are worn regularly.

However, overall effectiveness of hip protectors in the community setting was not established, probably due to incomplete adherence with use of the hip protectors, the inability of hip protectors to prevent hip fractures in a few cases, and the limited statistical power of the study.

In contrast to Kannus et al this trial was conducted using a more robust methodology and the estimate of effectiveness of hip protectors may be more reliable. This trial randomised individuals, did not replace dropouts, and did not replace participants who were non-adherent. However, the relative risk of hip fracture in a fall while wearing a hip protector compared with a fall while not wearing was 0.23 (95\% CI 0.08 to 0.72 ), which is very similar to the equivalent data in the Kannus et al paper which found a relative risk of 0.2 (95\% CI 0.05 to 0.50$)$. Moreover the confidence interval of our intention treat analysis ( 0.51 to 1.69 ) overlaps that of Kannus et al (0.2 to 0.8).

There was no increased risk of falls or non-hip fractures in the hip protector group, suggesting that use of hip protectors may not encourage risk taking behaviours. This was a potential concern as we have previously shown that use of hip protectors improves falls self efficacy. ${ }^{6}$ Adverse events are uncommon but some hip fractures occur despite use of correctly worn hip protectors.

We planned our study to have $80 \%$ power to detect a $50 \%$ reduction in risk of hip fracture. Unfortunately, the completed study had only $45 \%$ power to detect this relative risk reduction. The low power of our study resulted from recruitment of substantially fewer participants than planned (600 instead of 1000) and a lower hip fracture rate in the second year of follow up (3.3\%) than in the first year $(4.3 \%)$.

Our failure to find any effect of use of hip protectors on hip fracture risk despite $50 \%$ or better adherence may be due to lack of statistical power. Another explanation is that participants at highest risk were not wearing the protectors regularly. This is in contrast to other reports. ${ }^{47}$ Untruthful self reports of adherence is another explanation. However, the nurses collecting data about adherence did not believe that people were untruthful about adherence in many cases, as they were interviewed carefully about adherence on a number of occasions and, where possible, visits to assess adherence were made unannounced. There are many potential reasons for limited adherence ${ }^{12}$ but further examination of them will be reported in another paper.

Our results should be generalisable to routine use of hip protectors by frail older women, living in their own homes, who are using health services for older people. In order to take part in the trial potential participants needed to be ambivalent to the use of hip protectors as they were entering a randomised trial. As a result there was non-adherence from an early stage of the study by $19 \%$ of participants who were allocated to the intervention group.

\section{Key points}

- A number of studies conducted in nursing homes have shown that hip protectors reduce the risk of hip fractures.

- This randomised trial shows that use of hip protectors by people living in the community prevents hip fractures if the protectors are worn regularly.

- In this study the overall effectiveness of hip protectors in the community setting was not established.

- Factors limiting effectiveness of hip protectors in this study were incomplete adherence with use of the hip protectors, the inability of protectors to prevent hip fractures in a few cases, and limited statistical power.

Clinical and health service policy relating to the use of hip protectors in the community is quite different to residential aged care facilities (and hospitals). While the efficacy of hip protectors will be similar in all settings, actual effectiveness is likely to vary widely depending on adherence with their use. In residential aged care facilities cautious implementation of hip protectors, and further studies of interventions to improve adherence with their use, can be justified. In community and hospital settings randomised trials are needed, with hip fracture and adherence as the major outcomes. This is the first published study wholly conducted in a community setting. No controlled trials of hip protector use in hospitals have been reported.

Our conclusion is that it is reasonable to provide hip protectors to those older women living in the community who are at high risk of hip fractures, and who are strongly motivated to wear them. However, on the basis of our study findings, the routine use of hip protectors in all high risk community living older people is not justified.

\section{Authors' affiliations}

I D Cameron, Rehabilitation Studies Unit, University of Sydney, NSW, Australia

R G Cumming, S Quine, School of Public Health, University of Sydney, NSW, Australia

S E Kurrle, K Lockwood, Hornsby Ku-ring-gai Hospital, NSW, Australia T Finnegan, Royal North Shore Hospital, NSW, Australia

\section{REFERENCES}

1 Parker MJ, Gillespie LD, Gillespie WJ. Hip protectors for preventing hip fractures in the elderly (Cochrane Review). The Cochrane library. Oxford: Update Software, issue 4, 2002.

2 Kannus P, Parkkari J, Niemi S, et al. Prevention of hip fracture in elderly people with use of a hip protector. N Engl J Med 2000;343:1506-13.

3 Cameron ID, Quine S. Likely non-compliance with external hip protectors: findings from focus groups. Archives of Gerontology and Geriatrics 1994:19:273-81.

4 Hubacher M, Wettstein A. Acceptance of hip protectors for hip fracture prevention in nursing homes. Osteoporosis Int 2001;12:794-9.

5 March LM, Chamberlain A, Cameron ID, et al. Report from the Northern Sydney area fractured neck of femur health outcomes project. Sydney: Northern Sydney Public Health Unit, 1996.

6 Cameron ID, Stafford B, Cumming RG, et al. Hip protectors improve falls self-efficacy. Age Ageing 2000;29:57-62.

7 Lauritzen JB, Petersen MM, Lund B. Effect of external hip protectors on hip fractures. Lancet 1993;341:11-3.

8 Granger CV, Albrecht GL, Hamilton BB. Outcome of comprehensive medical rehabilitation: measurement by PULSES profile and the Barthe index. Arch Phys Med Rehabil 1979;60:145-54.

9 Pfeiffer $\mathbf{E}$. A short portable mental status questionnaire for assessment of organic deficit in elderly patients. J Am Geriatr Soc 1975;23:433-41.

10 Gandek B, Ware JE, Aaronson K, et al. Cross-validation of item selection and scoring for the SF-12 health survey in nine countries: results from the IQOLA poject (international quality of life assessment). J Clin Epidemiol 1998;51:1171-8

11 Cameron ID, Venman J, Kurrle SE, et al. Hip protectors in aged-care facilities: a randomised trial of use by individual higher-risk residents. Age Ageing 2001:30:477-81.

12 van Schoor NM, Deville WL, Bouter LM, et al. Acceptance and compliance with extrenal hip protectors: a systematic review of the literature. Osteoporosis Int 2002;13:917-24. 